\title{
(息)
}

Citation:

Martyn, P and Brymer, E (2016) The relationship between nature relatedness and anxiety. Journal of health psychology, 21 (7). pp. 1436-1445. ISSN 1359-1053 DOI: https://doi.org/10.1177/1359105314555169

Link to Leeds Beckett Repository record:

https://eprints.leedsbeckett.ac.uk/id/eprint/2605/

Document Version:

Article (Accepted Version)

The aim of the Leeds Beckett Repository is to provide open access to our research, as required by funder policies and permitted by publishers and copyright law.

The Leeds Beckett repository holds a wide range of publications, each of which has been checked for copyright and the relevant embargo period has been applied by the Research Services team.

We operate on a standard take-down policy. If you are the author or publisher of an output and you would like it removed from the repository, please contact us and we will investigate on a case-by-case basis.

Each thesis in the repository has been cleared where necessary by the author for third party copyright. If you would like a thesis to be removed from the repository or believe there is an issue with copyright, please contact us on openaccess@leedsbeckett.ac.uk and we will investigate on a case-by-case basis. 


\title{
The relationship between nature relatedness and anxiety
}

\begin{abstract}
This study investigated the relationship between anxiety and feelings of being connected to nature. Two standardised self-report scales, the Nature Relatedness Scale (NRS) and the State Trait Inventory for Cognitive and Somatic Anxiety (STICSA) were used in tandem with a qualitative question. Quantitative results indicated that connection to nature was significantly related to lower levels of overall, state cognitive and trait cognitive anxiety. Qualitative results revealed seven themes; relaxation, time out, enjoyment, connection, expanse, sensory engagement and a healthy perspective. Taken together these results suggest that opportunities which enhance experiences of being connected to nature may reduce unhelpful anxiety.
\end{abstract}

Keywords: connection to nature, anxiety, wellbeing, nature relatedness. 


\section{The relationship between nature relatedness and anxiety}

\section{Introduction}

Research from a wide range of disciplines indicates that nature-based experiences facilitate positive health and wellbeing outcomes (Brymer, Cuddihy, \& Sharma-Brymer, 2010; Health Council of the Netherlands \& Dutch Advisory Council for Research on Spatial Planning Nature \& the Environment, 2004; MIND, 2007; Orsega-Smith, Mowen, Payne, \& Godbey, 2004; Sugiyama \& Thompson, 2008; van den Berg, 2005). In particular, nature-based experiences boost mental health and psychological wellbeing (Roderer \& Cervinka, 2012; Bowler, Buyung-Ali, Knight \& Pullin, 2010) beyond benefits that physical activity alone would provide (Mitchell, 2013).

However, there is still uncertainty about the nature of this impact. This paper investigates the relationship between anxiety and feelings of being connected to nature. Results suggest that creating opportunities for connection to nature may be an effective intervention for state and trait anxiety. For this study, the term nature reflects the interpretations that underpin the nature relatedness scale where nature includes all non-human life including vegetation and animals (Nisbet, Zelenski \& Murphy, 2009).

Anxiety related issues are often severely debilitating and are fast becoming one of the most prevalent mental health concerns in the world (World Health Organization, 2011). Anxiety is conceptualised as both a state and trait phenomenon. State anxiety is a passing condition triggered by particular responses to stress and once the event has passed anxiety levels decrease. Trait anxiety is characterised by a stable susceptibility to the experience of anxiety (Spielberger \& Reheiser, 2009). While not all anxiety is troublesome, high intensity anxiety is linked to clinical disorders such as phobias and generalised anxiety disorder.

Anxiety has been further conceptualised in terms of cognitive and somatic symptom characteristics. Cognitive symptoms are associated with intrusive thoughts, worry, and low 
concentration and somatic symptoms include heart rate increases, stiff muscles, sweating and hyperventilation (Ree, French, MacLeod, \& Locke, 2008). State and trait anxiety are linked such that, increases in trait anxiety correlate with increases in state anxiety. This is reflected at both the cognitive and somatic levels (Ree, et al., 2008; Spielberger \& Reheiser, 2009). Accordingly, state and trait anxiety should be differentiated at the cognitive and somatic levels as they are aspects of anxiety which help explain overall increases in anxiety. For this study participants reported on overall anxiety in conjunction with the cognitive and somatic aspects of both state and trait anxiety.

There is little research that focuses on the link between nature and anxiety; however, there are theoretical perspectives that suggest nature-based experiences might facilitate reduced anxiety (Cervinka, Röderer \& Hefler, 2012). Most studies that have examined the natureanxiety relationship have done so as a small part of a much larger study (Cervinka, Röderer \& Hefler, 2012; Kuo, 2001; Ulrich, Simons, Losito, \& Fiorito, 1991; Zeller, 2006). Studies that have focused on anxiety have mostly undertaken experiments using physical activity in natural settings, such as parks. For example, Mackay and Neill (2010) measured the effect of different physical activities on anxiety levels using the state-trait anxiety inventory. They found that perceived naturalness of the environment was most important in reducing state anxiety. Exercise intensity and duration did not impact on state anxiety. Mackay and Neill (2010) postulated that outdoor "green" environments are positively associated with mental restoration. However, the level of participant fitness and the small sample size complicate the interpretation of the findings.

A study in the UK compared a walk in a country park with a walk in a shopping mall and found that $71 \%$ of participants reported lower levels of tension after a walk in the park whereas $50 \%$ reported increased tension after walking in a Mall. No participants reported an increase in tension after the walk in the park (MIND, 2007). Bowler et al. (2010) undertook a 
meta-analysis and established that nature-based activities are more likely linked to lower anxiety levels in than indoor activities. In summary, studies that have examined the relationship between anxiety and physical activity in nature have focused on state anxiety and determined that activities in nature are correlated with reduced state anxiety over and above the effects of exercise.

A variety of theoretical perspectives have been used to explain how nature-might enhance positive mental health and potentially reduce anxiety. For example, attention restoration theory (ART) (Kaplan \&Kaplan, 1989) and psycho-evolutionary theory (PET) (Ulrich, 1993) propose that nature is mentally restorative and prevents stress related illnesses like anxiety (Hartig, Mang, \& Evans, 1991; Herzog, Black, Fountaine, \& Knotts, 1997; Karmanov \& Hamel, 2008; Ulrich, 1984). Those espousing ART propose that urban environments deplete attentional capacity, however interactions in nature promote effortless attention, which is restorative (Herzog, et al., 1997). PET suggests that human beings have innate preferences for natural landscapes, which are associated with safety and as such are non-stress inducing (Kahn, Severson, \& Ruckert, 2009).

The biophilia hypothesis (Wilson, 1984) proposes that human beings are innately connected to nature and that experientially realising this connection is essential for physical, psychological, and spiritual health ( Frumkin, 2001; Heerwagen \& Orians, 1993; Pretty, 2002). Connection to nature refers to the extent nature is part of a person's identity or cognitive representation (Schultz, 2002; Scott, 2010). Awareness of this ecological identity and feelings of connectedness are associated with positive mental health.

Roszak (1992) popularised the term ecopsychology to examine the relationship between psychological health and connection to nature. Proponents of ecopsychology argue that activities that enhance engagement with the natural world increase feelings of connection to nature. From this perspective, the natural world is not separate from humanity; but it is at the 
very core of humanity, even if we live in a material and cultural world which may attempt to deny recognition of this fact. Feelings of connection, unity or being a part of the natural world, according to this perspective, are a causal step to psychological health (Feral, 1998).Thus feelings of connection to nature would be expected to correlate with reduced anxiety (Besthorn \& Canada, 2002; Mayer \& Frantz, 2004; White, 2011). As anxiety is a mental health problem with increasing prevalence, creating further understanding of the anxiety-nature relationship would be beneficial. Whilst previous research has focused on state anxiety, the aim of this present study was to extend this research by including assessment of both state and trait aspects of anxiety, as well as cognitive and somatic aspects of anxiety, in relation to connection to nature.

\section{Method}

Participants

Participants were recruited through student networks at an Australian university and the Australian Psychological Society (APS), Participants ( $\mathrm{n}=305)$ ranged in age from 18 to 79 (M $=33.53, \mathrm{SD}=15.71)$. Females represented $78.7 \%$ of the sample.

\section{Materials}

Participants completed a survey consisting of quantitative questions, one qualitative question and a request for demographic information. The aim of collecting qualitative data was to identify categorical themes from the statement "In your own words please tell us what being in nature means to you" (Castro \& Coe, 2007). The qualitative question was worded in a broad, open fashion in order to minimise the chances of leading responses and allow for a range of responses including the possibility that being in nature may have no relationship to anxiety or the reduction of anxiety. 
Two quantitative scales were utilised, the Nature Relatedness Scale (NRS) which measured an individual's relatedness to nature and the State Trait Inventory for Cognitive and Somatic Anxiety (STICSA) which measured overall anxiety as well as somatic and cognitive aspects of state and trait anxiety. The NRS is a 21 item scale, that measures the "affective, cognitive, and physical relationship individuals' have with the natural world" (Nisbet, Zelenski \& Murphy, 2009, p. 719). The NRS consists of three subscales including: an 8-item subscale "self" which measures personal connection to nature, a 7-item subscale "perspective" which measures external worldviews of nature, and a 6-item subscale "experience" which measures physical familiarity with nature. Each subscale uses a 5-point Likert scale ranging from 1 (disagree strongly) to 5 (agree strongly). Scores are summed to range from 21-105 whereby higher scores indicate a stronger connection with nature.

The STICSA comprises two scales with 21 items each rated on a 4-point Likert scale ranging from 1 (not at all) to 4 (very much so). The STICSA produces a score from 42-168 whereby higher scores indicate higher anxiety (Ree, et al., 2008). The first scale assesses how people feel at the time of taking the survey (state anxiety) even if it is not how people usually feel, and the second scale predicts situations in which individuals will have elevated anxiety (trait anxiety). Within each scale, anxiety is separated into two subscales comprising 10 cognitive items and 11 somatic items. The STICSA reliably differentiates between state and trait anxiety with Cronbach's alpha coefficients reported of greater than .86 for each scale. The STICSA was also shown to be a reliable and valid scale in confirmatory factor analyses with clinical and college samples (Gros, Antony, Simms, \& McCabe, 2007; Gros, Simms, \& Antony, 2010). The STICSA has been validated as a good measure of anxiety with excellent clinical and non-clinical psychometric properties (Van Dam, Gros, Earleywine, \& Antony, 2013) 


\section{Design and Procedure}

The survey was administered online. As recommended in a concurrent nested mixed method design, quantitative data were prioritised over qualitative data (Hanson, et al., 2005).

Quantitative data were analysed followed by thematic analysis of qualitative data.

Bivariate correlations were used to investigate quantitative data. Data were analysed using the Statistical Package for the Social Sciences (SPSS version 17.0). The Qualitative comments were analysed using the thematic analysis process (Creswell, 2009). Initially, comments were read to gather a general sense of what was being said. Descriptive categories were chosen based on the aim of the study which was to explore the relationship between nature and anxiety (Shaughnessy, Zechmeister, \& Zechmeister, 2009). Results were cross checked by two coders in order to increase reliability as multiple category responses were collapsed into fewer themes with multiple levels. Finally, quantitative and qualitative data were integrated to assist overall interpretation of results (Creswell, 2009).

\section{Results}

This study examined the relationship between connection to nature and anxiety. In the current study, the observed internal consistency for the STICSA was satisfactory, with Cronbach's alpha ranging from .68 to .93 . In the following sections the quantitative and qualitative results will be discussed and implications for different aspects of anxiety and overall anxiety will outlined.

\section{Quantitative Results}

Table 1 presents the descriptive statistics of the NRS and STICSA subscales used for the analyses. Normality was investigated visually via histograms and statistically via Kolmogorov-Smirnov statistics and follow-up skew and kurtosis statistic assessments. Both 
the state and trait somatic subscales of the STICSA showed notable positive skew and leptokurtosis. Bootstrapping was used to calculate confidence intervals for descriptive statistics to provide more stable estimates given this deviation from normality.

Insert Table 1

Bivariate correlations between variables were examined via both Pearson's and Spearman's correlation analysis for comparative purposes given the normality breaches for the two somatic anxiety subscales of the STICSA (Allen \& Bennett, 2010). No notable differences were found in the direction and relative strength of these relationships.

The results displayed in Table 2 show statistically significant strong positive intercorrelations between the STICSA subscales as would be expected as well as moderate to strong inter-correlations between the NRS subscales. Slightly stronger correlations were noted between the self and experience subscales of the NRS and the STICSA subscales compared to those with the perspective subscale of the NRS.

Insert Table 2

In order to more fully explore the relationship between the NRS subscales and the STICSA subscales, four standard multiple regressions were conducted with the three NRS subscales as predictors for each of the four subscales of the STICSA in turn. Bootstrapping was used to counter any normality breaches. No influential multivariate outliers were found for any of the regression analyses. Table 3 presents the findings of the four regressions for comparative purposes. Overall, a relatively small percentage of variance in STICSA subscales was 
explained by NRS subscales, with a larger proportion state (11\%) and trait (9\%) cognitive anxiety explained than somatic anxiety ( $3 \%$ to $5 \%$ ). Within the analyses of cognitive anxiety it was the NRS experience subscale which provided the largest and only individually significant prediction to the regression models.

Insert Table 3

Qualitative Results

Qualitative results were explored in order to gain a broader perspective of participants' view of connection to nature and, if appropriate, to help explicate the nature-anxiety relationship. In this context, participants were asked to reflect on what being in nature meant to them. Seven major themes were identified: relaxation, time out, enjoyment, connection, healthy perspective, sensory engagement, and expanse. Themes were developed based on sub-themes and characteristic phrases that recurred around a central theme (see Table 4).

Insert Table 4

\section{General explication of themes}

In this study the various themes had multiple elements, e.g., relaxation included de-stress, peace, calm, renewal, re-grounding, and fulfillment. Within each theme, there were sometimes secondary or even tertiary effects for participants e.g., time out also induced relaxation and peacefulness. Other differences which could be identified related to the importance of nature to participants. These different levels of importance were: (a) deep level, for some participants nature was highly important and made a difference to their 
everyday life; (b) intermediate level, nature was important for its beneficial effect but was not reported as being essential; and (c) minor level, nature was not considered more important than any other aspect of life but was still reported as having a beneficial effect. Some themes were about nature inducing the particular feeling e.g., relaxation.

In the main, participants in this study reported that nature induced relaxation and acted as a relief from stress. Nature was also described as being responsible for feelings of peace and calm. Some participants indicated that nature provided a sense of renewal, was re-grounding, and created feelings of fulfilment.

Another important theme was "time out" which related to nature providing a sense of being away from the everyday, escape, and refuge. Participants saw being in nature as being away from the urban environment and providing a sense of freedom. For most participants being away from everyday life was important on its own, however, for some there were other benefits such as peacefulness and relaxation.

The theme of enjoyment suggested being in nature created feelings of joy, happiness, and contentment. For most participants enjoyment of nature was important because it was associated with secondary and sometimes tertiary effects. Being in nature also induced a sense of fulfilment from the joy nature gave.

The theme of connection reflects being connected to something larger and revolved around feeling immersed, being part of something bigger, at one with, or connecting with what was important. Being connected to nature was occasionally spoken about in terms of being at one with the world which also had secondary benefits of feeling peaceful.

The theme of "healthy perspective" reflected a perception that nature was responsible for wellbeing and positive health. Those participants who mentioned the health benefits of nature considered that nature was very important to their everyday lives, their mental health, overall wellbeing, and fitness. 
The theme of "sensory engagement" suggested nature was stimulating to the senses and was associated with ideas of beauty. Nature was deeply and beneficially engaging of the senses for the majority of those participants who wrote about nature engaging the senses. This often included a spiritual aspect or a sense of the flawlessness of nature. For many participants in this study, nature provided an expansive sense of space. Nature allowed them to breathe fresh air, experience natural elements, such as sunshine, and find space to be alone.

\section{Discussion}

The relationship between connection to nature and anxiety was investigated using quantitative and qualitative methods. Results show that connection to nature was directly linked to lower overall anxiety levels, and lower levels of state cognitive anxiety and trait cognitive anxiety but not to lower levels of somatic forms of anxiety. These findings suggest that there is a negative relationship between connection to nature and overall anxiety. Accessing nature has contributed to state anxiety reduction in previous studies (see Chang \& Chen, 2005; Mackay \& Neill, 2010). The current study has found that feeling connected to nature is specifically linked to lower levels of state cognitive anxiety but not state somatic anxiety. In particular, the experience sub-scale of the nature relatedness scale was significantly related to lower levels of state cognitive anxiety. A possible explanation as to why somatic anxiety levels were not significantly related to connection to nature is that, in the case of the Australian portion of the sample, only $14.4 \%$ of people experience some sort of anxiety disorder over a 12 month period (Australian Bureau of Statistics, 2007). As such, at the time of taking the survey the majority of Australian participants were unlikely to have been anxious enough to report somatic symptoms. Furthermore, as cognitive anxiety symptoms are a precursor to somatic anxiety symptoms, cognitive anxiety symptoms would be detected before somatic symptoms were detected (Ree, et al., 2008). The relationship 
between low cognitive anxiety and the nature relatedness scale suggests that physical interactions with nature or at least the recollection of physical comfort with nature might be the mediating factor in this finding. That is low state cognitive anxiety levels might be directly linked to positive experiences and recollections of actual experiences in the natural world.

Results from this study suggest that connection to nature is also linked to lower levels of trait cognitive anxiety. No previous studies have considered the link between nature and trait anxiety. The current study has detected significant cognitive but not somatic differences in trait anxiety with connection to nature. As with the state anxiety findings, this study also found that the experience sub-scale of the nature-relatedness scale was most significantly linked to lower levels of trait cognitive anxiety. This suggests that either people with lower anxiety levels are more easily able to experience connection to nature, or that cognitive aspects of state and trait anxiety are closely related to experiences of connection to nature. The relationship between lower levels of trait cognitive anxiety and experiences in nature would also suggest that the physical relationship with nature is most important. Results from this study suggest that experiences that involve interacting with or relating with nature in a manner that enhances feelings of physical familiarity are vital.

The qualitative results suggest that the experience of nature for these participants provides an opportunity to take time out from everyday life, recuperate, experience fun and relax. These elements might explain how nature experiences are related to low levels of cognitive anxiety. In line with observations made by Rodere and Cervinka (2012) this study suggests that experiences in nature might afford restorative opportunities and space for a more effortless attention. 


\section{Theoretical Perspective}

In the current study, the quantitative results are supportive of PET and ART in that feeling connected to nature is correlated with lower levels of cognitive state and trait anxiety, and overall anxiety. These findings are supportive of the reductions in state anxiety and overall anxiety that has been found in previous studies (Chang \& Chen, 2005; Mackay \& Neill, 2010). No previous research has addressed the cognitive aspect of state or trait anxiety in regard to nature. Furthermore, the qualitative results have helped to explicate the relationships which were found. These results are also supportive of the biophilia hypothesis and PET. In summary, feelings of being connected to nature were related to lower overall anxiety and cognitive anxiety. In the current study, connection to nature had beneficial effects for most participants. The results suggest that it might not be necessary to continually access nature to obtain the anxiety reducing benefits. Experiences that facilitate feeling connected to nature, and in particular feeling physical comfort with nature, may be sufficient to provide beneficial effects without having to continually access nature. It may also be possible for a person to feel connected to nature even when not in nature. In turn, these feelings of being connected to nature might act as a buffer against anxiety.

\section{Limitations}

Results report findings from a general population which was largely self-selected and as such it may be that only people who were interested in nature responded to the invitation to participate. However, this study raises important questions and illuminates tantalising possibilities which can be readily generalised to real world settings as more than $64 \%$ of the sample was from the general population. The anxiety measure (STICSA) was well validated, the data were complete, and two coders were used to cross check qualitative themes in order to reduce potential bias. Still, as the effects were small, it may be that other factors contributed to the anxiety and wellbeing of participants. Future research should consider 
whether to focus on cognitive aspects of anxiety rather than somatic anxiety. Future research might also explore the qualitative experience of participants with the aim of eliciting a more in-depth understanding of how nature-based experiences might help reduce anxiety. Future research might also focus on a nature-based intervention designed to enhance connection to nature and physical comfort with nature in order to investigate if an experience of interacting with nature enhances connection to nature and lowers cognitive aspects of state and trait anxiety.

\section{Conclusion}

The results of this study align with recent research and theoretical perspectives that posit health and wellbeing benefits from engaging with nature. In particular, this study adds clarification to the nature-anxiety relationship by demonstrating that connection to nature is directly related to small reductions in overall anxiety, and cognitive aspects of state and trait anxiety. The results also support the idea that people who report being connected to nature are less anxious whereas previous research suggested that people need to access nature in some way for anxiety to be reduced. Qualitative results suggest that connection to nature is essential for mental wellbeing, and reductions in anxiety. Further, this study suggests that experiences that encourage physical interaction and feelings of physical comfort with nature might be most appropriate for managing unhelpful anxiety.

\section{References}

Allen, P., \& Bennett, K. (2010). PASW statistics by SPSS: A practical guide: Version 18.0

(1st ed.). South Melbourne, Vic: Cengage Learning Australia. 
Besthorn, F. H., \& Canada, E. R. (2002). Revisioning environment: Deep ecology for education and training in social work. Journal of Teaching in Social Work, 22, 79101.

Bowler, D., Buyung-Ali, L., Knight, T. \& Pullin, A.S. (2010). The importance of nature for health: is there a specific benefit of contact with green space? CEE review 08-003 (SR40). Environmental Evidence: www.environmentalevidence.org/SR40.html

Brymer, E., Cuddihy, T. F., \& Sharma-Brymer, V. (2010). The role of nature-based experiences in the development and maintenance of wellness. Asia-Pacific Journal of Health, Sport and Physical Education, 1, 21-27.

Castro, F. G., \& Coe, K. (2007). Traditions and alcohol use: A mixed-methods analysis. Cultural Diversity and Ethnic Minority Psychology, 13, 269-284.

Cervinka, R., Röderer, K., \& Hefler, E. (2012). Are nature lovers happy? On various indicators of well-being and connectedness with nature. Journal of Health Psychology, 17: 379-388,

Chang, C. Y., \& Chen, P. K. (2005). Human responses to window views and indoor plants in the workplace. Horticultural Science, 40, 1354-1359.

Creswell, J. W. (2009). Research design: Qualitative, quantitative, and mixed methods approaches (3rd ed.). Thousand Oaks, California: Sage.

Feral, C. (1998). The connectedness model and optimal development: Is ecopsychology the answer to emotional well-being? The Humanistic Psychologist, 26, 1-3,

Frumkin, H. (2001). Beyond toxicity: Human health and the natural environment. American Journal of Preventive Medicine, 20, 234-240.

Gros, D. F., Antony, M. M., Simms, L. J., \& McCabe, R. E. (2007). Psychometric properties of the State-Trait Inventory for Cognitive and Somatic Anxiety (STICSA): 
Comparison to the State-Trait Anxiety Inventory (STAI). Psychological Assessment, 19, 469-381.

Gros, D. F., Simms, L. J., \& Antony, M. M. (2010). Psychometric properties of the StateTrait Inventory for Cognitive and Somatic Anxiety (STICSA) in friendship dyads. Behavior Therapy, 41, 277-284.

Hanson, W. E., Creswell, J. W., Plano Clark, V. L., Petska, K. S., \& Creswell, J. D. (2005). Mixed methods research designs in counseling psychology. Journal of Counseling Psychology, 52, 224-235.

Hartig, T., Mang, M., \& Evans, G. W. (1991). Restorative effects of natural environment experiences. Environment and Behavior, 23, 3-26.

Health Council of the Netherlands and Dutch Advisory Council for Research on Spatial Planning, Nature and the Environment. (2004) Nature and Health. The influence of nature on social, psychological and physical well-being. The Hague: Health Council of the Netherlands and RMNO, publication no. 2004/o9E; RMNO publication nr Ao2ae. Heerwagen, J. H., \& Orians, G. H. (1993). Humans, habitats, and aesthetics. In S. R. Kellert \& E. O. Wilson (Eds.), The biophilia hypothesis (pp. 138-172). Washington, DC: Island Press.

Herzog, T. R., Black, A. M., Fountaine, K. A., \& Knotts, D. J. (1997). Reflection and attentional recovery as distinctive benefits of restorative environments. Journal of Environmental Psychology, 17, 165-170.

Kahn, P. H., Jr., Severson, R. L., \& Ruckert, J. H. (2009). The human relation with nature and technological nature. Current Directions in Psychological Science, 18, 37-42.

Kaplan, R., \& Kaplan, S. (1989). The experience of nature: A psychological perspective. Cambridge: Cambridge University Press. 
Karmanov, D., \& Hamel, R. (2008). Assessing the restorative potential of contemporary urban environment(s): Beyond the nature versus urban dichotomy. Landscape and Urban Planning, 86, 115-125.

Kuo, F. E. (2001). Coping with poverty. Environment \& Behavior, 33, 5-34.

Mackay, G. J., \& Neill, J. T. (2010). The effect of "green exercise" on state anxiety and the role of exercise duration, intensity, and greenness: A quasi-experimental study. Psychology of Sport and Exercise, 11, 238-245.

Mayer, F. S., \& Frantz, C. (2004). The connectedness to nature scale: A measure of individuals' feeling in community with nature. Journal of Environmental Psychology, 24. $503-515$

MIND. (2007). Ecotherapy: The green agenda for mental health Retrieved from http://www.mind.org.uk/assets/0000/2139/ecotherapy_executivesummary.pdf

Mitchell, R. (2013). Is physical activity in natural environments better for mental health than physical activity in other environments? Social Science \& Medicine, 91, 130-134

Nisbet, E., Zelenski, J., \& Murphy, S. (2009). The Nature Relatedness Scale: Linking individuals' connection with nature to environmental concern and behavior. Environment and Behavior, 41, 715-740.

Orsega-Smith, E., Mowen, A. J., Payne, L. L., \& Godbey, G. (2004). The interaction of stress and park use on psycho-physiological health in older adults. Journal of Leisure Research, 36, 232-256.

Pretty, J. (2002). Agri-culture: Reconnecting people, land, and nature. London: Earthscan. Ree, M. J., French, D., MacLeod, C., \& Locke, V. (2008). Distinguishing cognitive and somatic dimensions of state and trait anxiety: Development and validation of the State-Trait Inventory for Cognitive and Somatic Anxiety (STICSA). Behavioural and Cognitive Psychotherapy, 36, 313-332. 
Röderer, K. \& Cervinka, R. (2012). Mental Representations of Nature - The Importance of Well-Being. In S. Kabisch, A. Kunath, P. Schweizer-Ries, \& A. Steinführer (Eds.), Vulnerability, Risks, and Complexity: Impacts of Global Change on Human Habitats. Advances in People-Environment Studies, Volume 3 (pp. 243-254). Göttingen: Hogrefe

Roszak, T. (1992). The Voice of The earth: an exploration of ecopsychology. New York: Simon \& Schuster.

Schultz, P. W. (2002). Inclusion with nature: The psychology of human-nature relations. In P. Schmuck \& P. W. Schultz (Eds.), Psychology of sustainable development (pp. 61-78). Boston: Kluwer Academic.

Scott, B. A. (2010). Babes and the woods: Women's objectification and the feminine beauty ideal as ecological hazards. Ecopsychology, 2, 147-158.

Shaughnessy, J. J., Zechmeister, E. B., \& Zechmeister, J. S. (2009). Research methods in psychology (8th ed.). New York, New York: McGraw-Hill.

Spielberger, C. D., \& Reheiser, E. C. (2009). Assessment of emotions: Anxiety, anger, depression, and curiosity. Applied Psychology: Health and Well-Being, 1(3), 271-302.

Sugiyama, T., \& Thompson, C. W. (2008). Associations between characteristics of neighbourhood open space and older people's walking. Urban Forestry \& Urban Greening, 7, 41-51.

Ulrich, R. S. (1984). View through a window may influence recovery from surgery. Science, $224,420-421$.

Ulrich, R. S. (1993). Biophilia, biophobia, and natural landscapes. In S. R. Kellert \& E. O. Wilson (Eds.), The biophilia hypothesis (pp. 73-137). Washington, DC: Island Press. 
Ulrich, R. S., Simons, R. F., Losito, B. D., \& Fiorito, E. (1991). Stress recovery during exposure to natural and urban environments. Journal of Environmental Psychology, $11,201-230$.

Van Dam, N. T., Gros, D. F., Earleywine, M., \& Antony, M. M. (2013). Establishing a trait anxiety threshold that signals likelihood of anxiety disorders. Anxiety Stress Coping, 26(1), 70-86.

van den Berg, A. E. (2005). Health impacts of healing environments: A review of evidence for benefits of nature, daylight, fresh air, and quiet in healthcare settings. Retrieved from http://www.agnesvandenberg.nl/healingenvironments.pdf

White, P. R. (2011). A phenomenological self-inquiry into ecological consciousness. Ecopsychology, 3, 41-50.

Wilson, E. O. (1984). Biophilia: The human bond with other species. Cambridge: Harvard University Press.

World Health Organization. (2011). Mental health Gap Action Programme (mhGAP). from http://www.who.int/mental_health/mhgap/en/

Zeller, J. E. (2006). An exploration of the psychologically restorative qualities of the natural world. Doctoral dissertation. Available from Proquest Dissertations and Theses. (UMI No. 3217501) Proquest Dissertations and Theses. (UMI No. 3217501) database. 
